\title{
The Formation of the Geo-Space Data of Information Support Forecasting of Agricultural Territories
}

\section{Seytnazarov Kuanishbay Kenesbaevich,}

Doctor of technical Sciences of the Nukus branch Tashkent University of Information Technology named after Muhammad Al- Khorezmi, Nukus, Uzbekistan, seytnazarov82tuitnf@gmail.com

\section{Turdishov Dauletmurat Khojamuratovich,}

Senior Lecturer of the Department of Teaching Methods of Informatics Nukus State Pedagogical Institute named after Ajiniyaz, Nukus, Uzbekistan,dawletmurat@mail.ru

\section{Achilova Firuza Kurbanovna,}

Karshi of Branch of the Tashkent university of information technologies, Senior lecturer of the Department of Service of information technologies, Karshi, Uzbekistan, achilovaf@gmail.com

\section{ANNOTATION}

In this article there is given the problems which are solved with the geo-information systems. There is a huge number of GIS programs and tools that are successfully used and help in solving various technical problems. The solution of these forecast tasks, in our opinion, is very difficult without creating an automated information system for forecasting territories, which contains all of the above information that allows you to make the right management decisions and implement them. The highest modern technologies are available, gradually evolving and being introduced everywhere by confident steps.

\section{Keywords}

Geographic information systems, agricultural production, innovative technologies, multifactor, forecast, field maps, space, support, object, identification.

\section{INTRODUCTION}

Geographic information systems (GIS) are modern information technologies for mapping and analyzing real-world objects. Geo-information technologies are considered to be a natural and important element of any information system in which there is spatial data.

The agricultural region not only plays a huge role in the state economy, but also occupies an important role in human life, satisfying the human need for food, and there is also an industry for raw materials. Agriculture affects the Gross Domestic Product of the state. There had been developed: arable farming, crop production, vegetable growing, gardening. In the Republic of Uzbekistan, clear farming has been applied for two decades, and at present, clear farming covers new continents and countries. And all this is not in vain, due to the fact that proper farming not only simplifies the management of agriculture, but also reduces production losses. Regarding the Republic of Uzbekistan, this problem is the most relevant, the import substitution period has begun. For the effective development of agricultural production requires a highly efficient farming system with the introduction of innovative information 
technologies for collecting and processing information. As the world skill of introducing innovative technologies in agriculture shows, the use of remote sensing of territories highlights a large amount of superiority. When the Earth remote sensing system is introduced, the fields, hosts, crop types will be registered, the status of crops and soils will be monitored, zonality will be highlighted, the damage caused by the hurricane will be assessed, and the crop will be predicted and analyzed. But the most key positive is that the system reduces production losses.

The objective need to forecast agricultural areas is justified by the following main factors:

- increasing anthropogenic load on territorial resources;

- intensive environmental management and there is need to make higher demands on the system of observation and control over the state of natural and, in particular, territorial resources;

- there is need to isolate and reclaim anthropogenic changes in the state of the territories against the background of natural ones.

The main objectives of the territory forecast are included in the operational identification of changes in the state of the territories, their assessment, development of recommendations and management decisions for preventing and eliminating the consequences of negative processes, in information support of the state real estate cadastre, land management, land management and control over the use and protection of territories, and providing citizens with information on the state of the environment in terms of the state of the territories.

The system of precision farming, as international experience shows, provides a much greater economic effect, and most importantly increases the productivity of agricultural land, and vice versa reduces production costs. For example, with the introduction of the precision farming system in Germany, yields were increased by $30 \%$ while reducing the cost of mineral fertilizers by $30 \%$, fuel by $40 \%$ and inhibitors by $50 \%$.

Exact farming involves a lot of elements, but all of them can be divided into three main stages:

- collection of information about the farm, field, culture, region

- analysis of information and decision making - implementation of decisions - carrying out agro-technological operations.

To implement the technology of precision farming, modern agricultural equipment is required, managed by an onboard computer and capable of differentiating agricultural operations, precision positioning devices on the ground (GPS receivers), technical systems that help identify field heterogeneity (automatic samplers, various sensors and measuring systems, harvesting machines with automatic crop registration, remote sensing devices for agricultural crops, etc.) The core technology is accurate Farming (the second stage discussed above) is software that provides automated management of the spatial and attribute data of agricultural fields, as well as the generation, optimization and implementation of agro-technical solutions, taking into account the variability of characteristics within the cultivated field.

Maintaining a territory forecast is a set of measures for collecting, storing, processing and issuing large amounts of various information on any territory studied (individual farm, district, etc.). The results of such a forecast should contain information on the state of territorial resources, necessary and sufficient for making management decisions in the field of territorial relations at the level of regions and subjects.

\section{MATERIALS AND METHODS}

The solution of these forecast tasks, in our opinion, is very difficult without creating an automated information system for forecasting territories, which contains all of the above 
information that allows you to make the right management decisions and implement them. An effective tool for solving problems of a multifactor forecast of territories is a geographic information system (GIS), which is a hardwaresoftware complex that provides for the collection, processing, display and provision of information and operates on a single spatial-coordinated basis. Such a GIS, providing a system of knowledge of the territory in the form of digital data, combined into a set of layers that form an information model, can become the basis for creating an automated information system for forecasting agricultural areas. The creation of such a GIS is associated with the main content of this work.

Space forecasting technologies allow to effectively monitor various aspects of agricultural activity. Surveys from space provide an inventory of agricultural areas, the implementation of operational monitoring of the state of crops at various stages, allow you to identify the degradation processes of territorial resources, identify potential threats to crops and solve many other problems of the agro-industrial complex.

The objectives of the space forecast are divided into groups by industry and activity of the agro-industrial complex:

Accounting and use of agricultural areas:

- determine the exact boundaries of the fields and working areas with the calculation of areas;

- inventory and explication of agricultural areas;

- mapping of the real structure of territorial lands on agricultural lands (arable land, meadows, orchards, perennial plantings, deposits and unused land);

- mapping of crop rotations, determining the real structure of sown areas;

- identification of unused areas, control of rational use of agricultural land;

- identification of areas of overgrowth of agricultural areas with trees and shrubs, assessment of overgrowing of agricultural land; the allocation of areas of erosion, waterlogging, waterlogging, other manifestations of the degradation of territories;

- updating of soil maps, remote mapping of soil cover properties (organic matter content, development of erosion processes, degree of moisture);

identifying facts of unauthorized use of agricultural areas.

Crop production:

- monitoring the status of crops at different stages of the growing season (biomass growth, degree of moisture), including germination;

- planning and control of agro-technical works (plowing, harvesting);

- identification and prediction of adverse processes and phenomena (floods, pests) in order to take them into account when planning agricultural use of natural resources.

Irrigation and land reclamation:

- information support of design and survey works in the field of land reclamation and agricultural water supply;

- control and monitoring of the state of land reclamation and hydrotechnical objects.

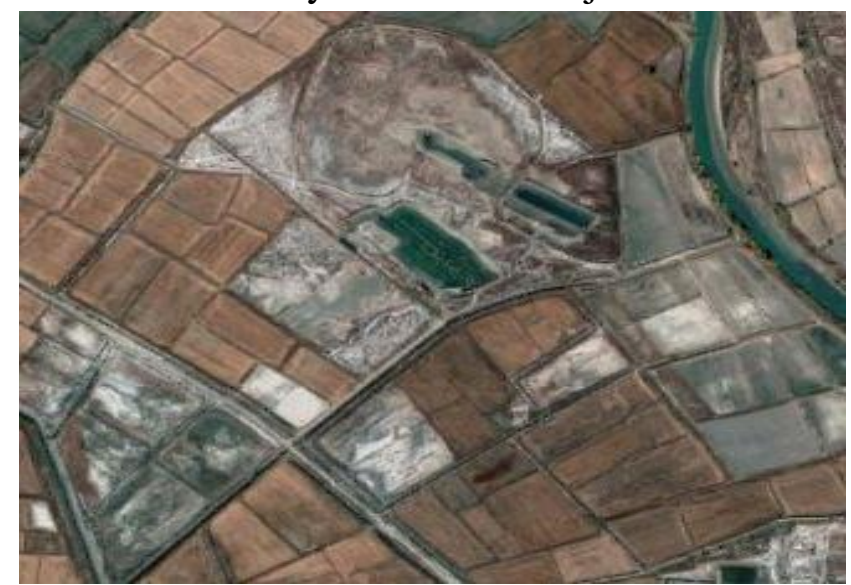

Figure 1. Sample satellite field image

Source: Snapshot ArgGIS The main advantages of remote sensing data for solving problems of agriculture: Efficiency. Actual satellite images can be obtained within a day after placing an order for a survey. 
- Objectivity. Information obtained from satellite images is a priori reliable and displays a real picture of the state of agricultural areas and vegetation.

- Lump sum and frequency. Modern satellite systems for remote sensing of the Earth allow high resolution imaging with very high frequency (up to 1 day).

- Uniformity. Space imagery data comes from calibrated sensors installed on satellites and does not need any additional transformations aimed at improving their mutual compatibility.

- Visibility. Modern satellite systems for remote sensing of the Earth make it possible to get a one-time survey on vast areas, which ensures the simultaneity of observations at production sites located at a considerable distance from each other.

Geographic information system (geographic information system, GIS) is a system for collecting, storing, analyzing and graphical visualization of spatial (geographic) data and related information about necessary objects.

The concept of a geographic information system is also used in a narrower sense - as a tool (software product) that allows users to search, analyze and edit both a digital map of the area and additional information about objects.

A geographic information system can include spatial databases (including those under the control of universal DBMS), raster and vector graphics editors, and various spatial data analysis tools. They are used in cartography, geology, meteorology, land management, ecology, municipal government, transport, economics, defense, and many other areas. The scientific, technical, technological and applied aspects of the design, creation and use of geographic information systems are studied by geoinformatics. Data in geographic information systems, as a rule, describe real objects, such as roads, buildings, water bodies, and forests. Real objects can be divided into two abstract categories: discrete (houses, territorial zones) and continuous (relief, precipitation, average annual temperature). To represent these two categories of objects, vector and raster data are used. Raster data is stored in the form of sets of values, arranged in the form of a rectangular grid. The cells of this grid are called pixels. The most common way to obtain raster data on the surface of the Earth is remote sensing, conducted using satellites. Raster data can be stored in graphic formats, such as TIFF or JPEG.

Vector data is usually much smaller than raster data. They are easy to transform and conduct binary operations on them. Vector data allows you to perform various types of spatial analysis, such as finding the shortest path in the road network. The most common types of vector objects are points, polylines, polygons. Points are used to designate geographic features for which location is important, not their shape or size. The ability to mark an object with a point depends on the scale of the map. While on the world map of the city it is advisable to designate point objects, on the map of the city the city itself is represented as a set of objects. In the GIS, a point object is depicted in the form of a certain geometrical figure of small dimensions (small square, circle, cross), or as an icon representing the type of a real object.

Semantic data can be tied to vector data: for example, on the map of territorial zoning, the area type characteristic can be tied to areal objects representing zones. The structure and data types are determined by the user. Based on the numerical values assigned to vector objects on the map, a thematic map can be built, on which these values are marked with colors in accordance with the color scale, or circles of different sizes. Continuous fields of values can be described by vector data. The fields are depicted as isolines or contour lines. One way of representing the terrain is an irregular triangulation grid (TIN, triangulated irregular networks). Such a grid is formed by a set of points with associated values (in this case, 
height). Values at an arbitrary point inside the grid are obtained by interpolating the values at the nodes of the triangle to which this point falls.

Agriculture is one of the most ancient types of human economic activity. Perhaps that is why we are seeing here a maximum of conservatism and a noticeable lag in the introduction of modern technologies, especially information. Of course, mechanization has significantly increased the productivity of rural labor, but if we compare it with how rapidly most industries develop, agriculture will be left far behind. Nevertheless, today and we already meet interesting projects that raise this type of production to a qualitatively new level. It is clear that the introduction of information technology should begin with a census of available production resources, with the creation of a database. Since the main resource in agriculture is land, such a database will necessarily be spatial in nature. Of course, you can renumber the fields and maintain a database of their characteristics in tabular form, even on paper. The introduction of computer technology allows not only to significantly simplify the introduction of information databases and reduce the likelihood of errors, but also to introduce new methods to support management decision-making based on data analysis and, ultimately, increase productivity. Since virtually all information on agricultural resources is spatially referenced, it is obvious that geographic information systems are best used as the basic information technology. The main advantage of modern GIS tools (first of all, ESRI technology) is in their openness and compatibility with other information technologies and data processing systems. Moreover, the scalability of ESRI solutions allows using different products of the same family at the most different levels of management.

The use of geo-information technologies in agriculture is possible at the regional, local levels, up to a separate vegetable garden. Since the tasks at these levels are different, respectively, the data and means of working with them are not the same. When using products of the same family (for example, ArcGis), both vertical (between different levels of management) and horizontal (between households or organizations of the same level) compatibility with data and software products is ensured.

The best use here could be found in server software products like ArcSDE and ArcIMS to support a centralized registry of agricultural areas, farm databases and fields. All these objects have a certain position and length in space, therefore only the technology of spatial databases can guarantee an adequate computer representation of this information. Moreover, a simple GIS package is not enough here - for example, in the USA there are tens of thousands of farms, millions of fields, and only special means of managing large spatial databases can cope with such volumes. This data must be provided with appropriate access. For this are the Internet technology. And the best solution for transmitting map data over the Internet and presenting maps on the Web is the ArcIMS Internet map server. Thanks to it, users of ArcGIS desktop products can access cartographic materials from anywhere in the world where there is an Internet connection. The same product can be used in the internal networks of organizations to provide access to cards on a central server via the Internet. At the level of an individual farm or group of farms, GIS technologies are also in demand, and now in industrialized countries one can observe a real boom called precision agriculture - precision farming. Its essence is that the processing of fields is made depending on the actual needs of the crops grown in this place. These needs are determined using modern information technologies, including space imagery, and often processing facilities are differentiated within different parts of the field, giving maximum effect with minimal damage to the environment and reducing the total consumption of substances used. The 
accumulation of processing statistics (where and how much each substance was contributed) and the results obtained (yield) allows the use of various types of analysis (regression, factor, etc.) in order to further adjust the applied doses to get the maximum return on each money invested in processing money. Modern DBMSs include statistical analysis tools that allow such an analysis to be carried out on individual fields.

\section{DISCUSSIONS AND RESULTS}

But if we want to make the analysis more detailed and accurate by dividing the fields into small homogeneous areas, then the spatial analysis tools available in ArcGIS will be required. This approach is considered optimal in the ideology of precision farming. And here it should be noted that two special additional modules of ArcGIS Spatial Analyst and Geostatistical Analyst implement the most modern methods of spatial data analysis, invisible to the naked eye. Using these tools for each elementary site, one can analyze the influence of the relief, soil characteristics, hydrological regime, history of the introduction of agrochemicals, as well as identify problem areas that do not fit into the existing agronomic model, and on this basis improve it. Using a single scalable software technology, such as ArcGIS, allows, on the one hand, to analyze any complexity and develop techniques using the most powerful products of the family (ArcInfo), and on the other - to provide end-users with minimum cost solutions (ArcView, ArcReader). It uses full compatibility between the various products of the family.

It is possible to identify not only temporal, but also spatial trends, to take into account the influence and interrelations of various factors not only in the temporal, but also in the spatial context.

An important factor in the informatization of agriculture, including the introduction of GIS, is the remoteness of users (farm specialists) from large cities with a developed information infrastructure. In this case, the possibilities of ESRI products for creating distributed geographic information systems and providing access to geodata via the Internet are very opportune. Products of the ArcGIS family can work with local data located on the same computer and with any data sets on the Internet. For field professionals, the ArcPad handheld application is useful.

Space images of electronic field maps provide an opportunity to keep strict records and control of all agricultural operations, because it relies on accurate knowledge of: field areas, road length, field information, etc. On the basis of the field map, a full analysis of the conditions affecting plant growth on this particular field (or even in areas of $100 \times 100 \mathrm{~m}$ or 10x10 m). Field maps form the basis for obtaining a crop rotation structure and serve to optimize production in order to maximize profits, as well as make rational use of all resources involved in production. Electronic maps of the fields make it possible to accurately plan, record and control all agricultural operations, since they rely on the objective dimensions of the fields, the length of roads and other objects applied to it in the process of creation.

Ways of drawing the boundaries of the working sections of the fields: - vectorization of the borders of the fields using a high resolution image;

- detour of field borders using GPS equipment and special software;

- combined method - a reasonable combination of the first two.

Within the framework of an integrated management system for an agricultural enterprise, electronic field maps are used to record crop rotation, to forecast mobile objects; for the organization of transportation, for yield mapping, for soil research, for statistical and thematic analysis of data, for planning the production process, etc. 
The use of most modern technologies in the field of precision farming is impossible without electronic field maps. With the use of electronic field maps, the agrochemical service, in a userfriendly way, can collect, classify and use information on crop rotation, crop yields, soil types, diseases, fertilizers applied and plant protection substances.

The functionality of the electronic field map:

- makes it possible to keep a strict record and control of all agricultural operations, since it relies on accurate knowledge of: the area of fields, the length of roads, information about fields, etc .; - helps to conduct a more complete analysis of the conditions affecting the growth of plants in this particular field (or even in areas of 100x100 m or 10x10 m);

- serves to optimize production in order to maximize profits, as well as the rational use of all resources involved in production.

Space images allow, in a mode close to real time, to obtain reliable information over large areas with a high degree of detail. According to satellite data after mathematical processing, you can build accurate land use maps. Sets of consecutive images provide an opportunity to assess changes in the use of territories and at the same time provide a forecast of crop productivity.

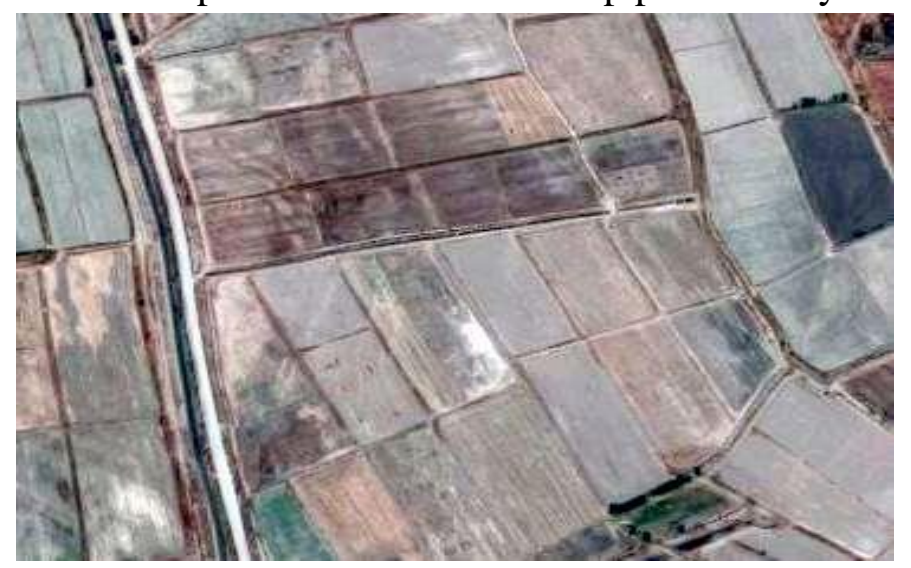

Source: screenshot of the program ArgGis

With the help of satellite forecast, it is possible to control the timing and quality of the main agricultural work and thereby optimize the management of agricultural production.

\section{CONCLUSION}

As a result, it should be noted that the GIS market is rapidly developing primarily in developed countries that want to reduce costs and expenses and get the maximum amount of product. In this they are helped by the remote sensing data, a huge number of GIS programs and tools that are successfully used and help in solving various technical problems. In our country, these developments in the past few years are also being actively pursued, but they are used infrequently and not everywhere. The reason for this is a low level of regional hardware, lack of specialists. However, technologies are available, gradually evolving and being introduced everywhere by confident steps.

\section{REFERENCE}

1. Giniyatov, I.A. Geoinformational support for the forecast of agricultural areas / I.A. Giniyatov, A.JI. Ilinykh // Bulletin of SGGA.-2011.-№ 1 (14). -C.3339.

2. Zhurkin, I. G. Geoinformation modeling and mapping of natural resource potential Text. / IG Zhurkin, JI. N. Chaban, V. S. Gruzinov // Geodesy and Cartography. 2008. - №7. - pp. 39-45.

3. Lurie, IK. Foundations of geoinformatics and the creation of GIS. Remote sounding and geographic information systems Text .: 4.1./ IK Lurie; by ed. A.M. Berlyant. M .: NEKS-92, 2002. - 140 p.

4. Experience of implementing GIS SOVZOND from the site http://sovzond.ru/services/gis/ogv/federal/sdmz/

5. Experience of implementing GIS Panorama from the site http://www.gisinfo.ru/item/85.htm

6. Dubrovsky A.V., Trotsenko E.S. Application of geoinformation systems for agricultural development and food security country security. Interexpo GeoSiberia, № 3, Volume 3, 2013, pp.67-69.

7. JiangPenghui; ChengLiang; Limanchun. Impacts of LUCC on soil properties in the riparian zones of desert oasis with remote sensing data: A case study of the middle Heihe River basin, China. SCIENCE OF THE TOTAL ENVIRONMENT Volume: 506 Pages: 259-271, Published: FEB 152015. 
8. Seytnazarov Kuanishbay Kenesbaevich, Dosymbetov Allayar Muxambetmustapayevich, Aytanov Anvar Kidirbayevich, Omarova Xawaxan Sulaymanovna, European Journal of Molecular \& Clinical Medicine, 2020, Volume 7, Issue 11, Pages 319-323, https://ejmcm.com/article_5057.html

9. Seytnazarov K.K., Turdyshov D.Kh, Aymurzaeva G.P, Formation of geospatial data for information support of agricultural land monitoring, Мухаммад Алхоразмий авлодлари 4(10)/2019, 29-32 page.

10. Idirisovich O.R, Abdixafizovich X.T, Bayramovich, S.D, Turdimuratovich A.A, (2020). Modeling the water resources contamination level in open nodes. European Journal of Molecular \& Clinical Medicine, 7(7), 673-680., https://ejmcm.com/article_3201.html

11. Turdyshov D.Kh. Information System of Farm Management, Modern problems of science and education, URL: www.science-education.ru/106-7616

12. Turdyshov D.Kh., Features of Construction Management Information, System Modern problems of science and education, URL: www.scienceeducation.ru/107-8187

13. Turdyshov D.Kh., Information Management System of Rice-growing farm, Modern problems of science and education, URL: www.science-education.ru/108$\underline{9055}$ 